\title{
Effect of aortic valve replacement on ventricular recovery and functional class in patients with reduced left ventricular function
}

\author{
Mahdi Ait Houssa ${ }^{1 *}$, Younes Moutakiallah ${ }^{1}$, Abdessamad Abdou' ${ }^{1}$ Abdedaïm Hatim², \\ Mohamed Drissi $^{2}$, Brahim Amahzoune ${ }^{1}$, Youssef El Bekkali ${ }^{1}$, Atif Benyass ${ }^{3}$, Abdelatif Boulahya ${ }^{1}$ \\ ${ }^{1}$ Cardiac Surgery Department, Mohammed V Military Hospital, Rabat, Morocco \\ ${ }^{2}$ ICU of Cardiac Surgery Department, Mohammed V Military Hospital, Rabat, Morocco \\ ${ }^{3}$ Cardiology Department, Mohammed V Military Hospital, Rabat, Morocco \\ Email: ${ }^{*}$ mahdiaithoussa@yahoo.fr
}

Received 22 October 2013; revised 25 November 2013; accepted 2 December 2013

Copyright (C) 2013 Mahdi Ait Houssa et al. This is an open access article distributed under the Creative Commons Attribution License, which permits unrestricted use, distribution, and reproduction in any medium, provided the original work is properly cited. In accordance of the Creative Commons Attribution License all Copyrights (C) 2013 are reserved for SCIRP and the owner of the intellectual property Mahdi Ait Houssa et al. All Copyright (C 2013 are guarded by law and by SCIRP as a guardian.

\section{ABSTRACT}

Objective: The aim of the study was to assess the effects of aortic valve replacement (AVR) in patients with aortic stenosis (AS) or regurgitation (AR) and left ventricular (LV) dysfunction. Patients and methods: Retrospective analysis identified 75 consecutive patients with left ventricular ejection fraction (LVEF) assessed by echocardiography $<40 \%$ who underwent AVR for AS $(n=40)$ or AR $(n=35)$ between 1994 and 2011. Exclusion criteria were previous myocardial infarction or concomitant valvular disorders other than aortic disease. Follow-up evaluated the New York Heart Association (NYHA) functional class, LVEF and survival rate. Results: Mean ages were respectively $56.5 \pm 9.3$ and $47.9 \pm 11.7$ years in AS and AR groups, $p=0.001$. Before surgery, $88 \%$ and $75 \%$ of patients were in NYHA III-IV respectively in AS and AR. In the AS group, the mean LVEF and aortic valve area (AVA) were respectively $32.2 \% \pm 8 \%$ and $0.65 \pm 0.15 \mathrm{~cm}^{2}$. AR group had a mean LVEF of 33.8 $\pm 6.7 \%$ and a mean $L V$ systolic diameter of $62 \pm 8.8$ mm. All patients underwent AVR under cardiopulmonary bypass. There were 5 operative deaths $(\mathbf{1 2 . 5 \% )}$ in AS group and $6(\mathbf{1 7 . 6 \% )}$ in AR group, $p=$ 0.57. LVEF increased to $49 \% \pm 14.7 \%$ and $51.2 \% \pm$ $10.9 \%$ in the AS and AR groups after echocardiography control. The survival rates at 1,5 and 10 years were respectively $94.4 \%, 87 \%$ and $80 \%$ in AS group and $95.2 \%, 93 \%$ and $89 \%$ in AR group. Conclusion: Despite higher perioperative mortality in patients with aortic valve disease (AS or AR) and LV dysfunc-

*Corresponding author. tion, long-term outcome is excellent. We, therefore, conclude that AVR can be performed and it should not be denied to patients on the basis of low EF alone.

Keywords: Aortic Valve Disease; Aortic Valve Replacement; Left Ventricular Dysfunction

\section{INTRODUCTION}

Congestive heart failure (CHF) is one of the leading causes of hospitalization in western countries and is associated with significant morbidity and mortality. The most common causes of CHF are ischemic heart diseases. A small minority of patients, about $5 \%$, have $\mathrm{CHF}$ as a result of valvular disorders [1]. Contrary to the developed countries, rheumatic heart valvular disease is often the main etiology of heart diseases in developing countries.

With the advent of better surgical techniques and improved preoperative and postoperative medical management, traditional surgeries for patients with severe LV dysfunction can actually be performed with reasonable success. When LV function is dramatically reduced, LV assist devices either as end stage device or as a bridge to transplant and heart transplantation are generally considered the choice of last resort in heart management. In our country, those therapeutic options are not available. In the same way, new innovative approach, such as percutaneous implantation of an aortic valve prosthesis commonly called TAVI transcatheter aortic valve implantation is more expensive and didn't start yet in our country, and in addition, our patients are younger than occidental 
people, with less comorbidities which limit their indication. For those reasons, standard AVR is the only effective treatment recommended in patients with severe AS and severe AR associated with depressed ventricular ejection.

Few studies have compared the results for the different valvular disorders in the subgroup of patients suffering from AS and AR associated with reduced ventricular function [2-4].

\section{PATIENTS AND METHODS}

\subsection{Study Population}

Between January 1994 and December 2011, 384 consecutive patients underwent isolated AVR at the present author's department. Of this population, 75 consecutive patients $(19.5 \%)$, who had severe AS or severe AR associated to reduced LV function (LVEF $<40 \%$ ) were included. Concomitant coronary artery bypass graft (CABG) for angina pectoris secondary to coronary artery stenosis was not excluded. Patients were excluded if they had a history or clinical evidence of previous acute myocardial infarction (AMI), combined valvular operations other than AVR, redo aortic valve surgery or were $<18$ years old.

All patients underwent transthoracic echocardiography (TTE) at the admission to the hospital by an experienced cardiologist. Measurements of the LV dimensions were made from 2D TTE images in the parasternal long axis view and EF was calculated by modification of simpson's method with two apical views. Aortic valve hemodynamics was assessed by Doppler echocardiographic examination. The maximal trans-aortic valve gradient was calculated from the peak aortic Doppler velocity by the modified Bernouilli equation and mean aortic pressure gradient was also measured by the similar method. AVA was calculated with the continuity equation. The grade of AR was evaluated with color Doppler.

\subsection{Operative Technique}

Standard anesthesia and surgical techniques were employed. Moderate hypothermia $\left(32^{\circ} \mathrm{C}\right)$ cardiopulmonary bypass (CPB) was used in all patients, with classic approach via a median sternotomy. Myocardial protection technique varied during the study period. From 1994 until 2002, we employed antegrade intermittent crystalloid cardioplegia (cold saint Thomas II). But since 2003, intermittent hyperkalemia cold blood cardioplegia was administered in most cases. When CABG was required, proximal anastomoses were performed before removal of the aortic cross clamp.

Postoperative and follow-up data:

Hospital mortality was defined as death at any time before discharge from the hospital. Death attributed to CHF,
AMI, arrhythmia and neurological complications were considered as cardiovascular deaths, as was sudden death without specific cause. Most of the survivors were prospectively investigated by a visit or telephone interview, including physical examination, chest $\mathrm{X}$ radiogram and echocardiogram.

\subsection{Statistics}

Statistical analysis was performed using the statistical software package of social science (SPSS 11.5, Chicago, Illinois, USA). All data were expressed as mean \pm standard deviation, median or prevalence as appropriate. Continuous variables were analyzed by the student's $t$ test when the variable distribution was found to be normal; otherwise a non parametric Mann-Whitney U test was used. Categorical variables were compared between groups by the $\chi^{2}$ test for independence or by Fisher's exact test when appropriate. The survival curve was analyzed using the non parametric Kaplan-Meier test. A p value of 0.05 or less was considered to be significant.

\section{RESULTS}

Preoperative patient's characteristics and operative data are summarized in Tables $\mathbf{1}$ and 2. Seventy five patients

Table 1. Preoperative characteristics of the patient population and comparison between AS and AR.

\begin{tabular}{cccc}
\hline Variable & AS (n=40) & AR $(\mathrm{n}=35)$ & $\mathrm{p}$ \\
\hline Age (years) & $56.5 \pm 9.3$ & $47.9 \pm 11$ & 0.001 \\
Sex (Female/Male) & $5 / 30$ & $8 / 40$ & 0.41 \\
BMI (Kg/m $\left.{ }^{2}\right)$ & $24.8 \pm 3$ & $23.7 \pm 4.2$ & 0.2 \\
NYHA III-IV (\%) & $88 \%$ & $75 \%$ & \\
Diabetes (n, \%) & $8(20 \%)$ & $1(2 \%)$ & 0.024 \\
Hypertension (n, \%) & $8(20 \%)$ & $5(14 \%)$ & 0.38 \\
Renal failure (n, \%) & $8(20 \%)$ & $3(8.5 \%)$ & 0.36 \\
PVD (n, \%) & $7(17.5 \%)$ & $2(5.7 \%)$ & 0.11 \\
LVEDD (mm) & $63.6 \pm 8.9$ & $77.6 \pm 9.8$ & 0.001 \\
LVESD (mm) & $50.2 \pm 9.2$ & $62 \pm 8.8$ & 0.001 \\
Ejection fraction (\%) & $32.2 \pm 8$ & $33.8 \pm 6.7$ & 0.34 \\
Aortic valve area (cm $\left.{ }^{2}\right)$ & $0.65 \pm 0.15$ & - & - \\
Mean TVG & $42 \pm 12.9$ & - & - \\
Aortic regurgitation & & & \\
- $\quad$ & & $13(37.1 \%)$ & - \\
Grade III (n, \%) & 0 & $22(62.9 \%)$ & - \\
Grade IV (n, \%) & 0 & $48.8 \pm 14.6$ & 0.85 \\
PAP Systolic pressure (mmHg) & $49.6 \pm 15.6$ & 48.05 & 0.013 \\
CT index & $0.58 \pm 0.05$ & $0.62 \pm 0.05$ & 0.09 \\
Euroscore & $7.15 \pm 3.8$ & $5.77 \pm 2.9$ & 0.09 \\
Logistic regression Euroscore & $11.8 \pm 10$ & $9.04 \pm 8.7$ & 0.23 \\
Creatinine (mg/dl) & $12 \pm 4$ & $14 \pm 7.4$ & 0.15 \\
Angina pectoris (n, \%) & $10(25 \%)$ & $5(14.2 \%)$ & \\
\hline
\end{tabular}

BMI: body mass index, NYHA: New York Heart Association, PVD: pulmonary vascular disease, LVEDD: left ventricular end-diastolic diameter, LVESD: left ventricular end-systolic diameter, TVG: transvalvular gradient, PAP: pulmonary artery pressure, CT: cardio-thoracic. 
Table 2. Comparison of perioperative data between AS and AR.

\begin{tabular}{cccc}
\hline Variable & AS (n = 40) & AR (n =35) & $\mathrm{p}$ \\
\hline Non elective operation (n, \%) & $8(20)$ & $5(14.2)$ & 0.36 \\
CPB time (min) & $96.4 \pm 35$ & $101 \pm 46$ & 0.63 \\
X clamp time (min) & $66 \pm 25$ & $66.7 \pm 26$ & 0.93 \\
Operation time (min) & $179.5 \pm 60.8$ & $204.7 \pm 67$ & 0.16 \\
Aortic prosthesis size (mm) & $22.3 \pm 1.5$ & $23.4 \pm 1.3$ & 0.002 \\
Concomitant CABG (n, \%) & $7(17.5 \%)$ & $1(2.9 \%)$ & 0.11 \\
Aortic enlargement (n, \%) & $1(2.5 \%)$ & 0 & 0.52 \\
Mechanical ventilation time (h) & $18(8-24)$ & $13.5(6.25-25)$ & 0.43 \\
Mechanical ventilation > 48h (n, & $8(20 \%)$ & $8(22.8 \%)$ & 0.77 \\
ICU stay (days) & $48(30.7-76.5)$ & $48(24-72)$ & 0.19 \\
Hospital stay (days) & $13.12 \pm 7$ & $10.7 \pm 2.3$ & 0.066 \\
LOS n (\%) & $16(40 \%)$ & $13(37 \%)$ & 0.53 \\
IABP n (\%) & $3(7.5 \%)$ & $3(8.5 \%)$ & 0.58 \\
Reoperation for bleeding (n, \%) & $0(0 \%)$ & $1(2.5 \%)$ & 0.54 \\
Deep wound infection (n, \%) & $3(7.5 \%)$ & $2(5.7 \%)$ & 0.59 \\
New renal failure (n, \%) & $4(10 \%)$ & $5(14.2 \%)$ & 0.65 \\
Hospital mortality (n, \%) & $5(12.5 \%)$ & $6(17.6 \%)$ & 0.57 \\
Aortic root repair (n, \%) & $1(2.5 \%)$ & 0 & \\
\hline
\end{tabular}

CPB: cardiopulmonary bypass, $\mathrm{X}$ clamp: cross clamping, CABG: coronary artery bypass graft, ICU: intensive care unit, LOS: low output syndrome, IABP: intra-aortic balloon pump.

with LVEF $<40 \%$ were identified. This cohort represents $19.5 \%$ of the total number of patients who underwent isolated AVR at our institution over the period of the study. Forty patients (53.4\%) had severe AS and thirty five $(46.6 \%)$ had AR. The two groups were similar with most preoperative and operative characteristics. The AS patients were significantly older and had also a higher incidence of diabetes. But the AR had large diameters of LV and more advanced symptoms as indicated by NYHA functional class. The most common etiology in both groups was rheumatic disease. Seventy three patients receiving mechanical prosthesis were implanted in the AS group. Eight patients (10.8\%) required concomitant CABG (7 in AS and 1 in AR). No differences regarding the need for excessive inotropic supports or intra-aortic balloon pump or other complications were observed.

\section{Postoperative Course, Early and Late Outcome}

The 30-day mortality was $14.6 \%$ (11/75). All patients died of low cardiac output syndrome (LOS) and multiorgan failure (MOF). There was no significant difference in the operative mortality between the two groups: $12.5 \%$ $(5 / 40)$ in the AS patients and $17.6 \%(6 / 35)$ in the AR patients, $\mathrm{p}=0.57$.

The postoperative complications were similar between the two groups. The mean aortic prosthesis size was different (AS: $22.3 \pm 1.5$ vs AR: $23.4 \pm 1.3, \mathrm{p}=0.002$ ). Among survivors, the survival rate at 1,5 and 10 years was respectively $94.4 \%, 87 \%$ and $80 \%$ in AS group and
95.2\%, $93 \%$ and $89 \%$ in AR group.

In the AS group mean follow-up time was $31.8 \pm 22$. Three patients died during follow-up; among those, one died from hemorrhagic stroke, one from prosthetic valve thrombosis and one from cancer.

In the AR group, the mean follow-up period was 61.8 \pm 45 months. During follow-up, 3 patients died: of those, two from CHF and one from severe sepsis and MOF secondary to late prosthetic valve endocarditis.

Clinical and echocardiographic follow-up was complete $79 \%$ among survivors. Symptomatic improvement was noted in most of the survivors (Table 3). Eighty one percent $(81 \%)$ were severely symptomatic (FC NYHA III-IV) before surgery and only $4.7 \%$ after control.

There is the significant change in NYHA functional class (Figure 1). In AS, preoperative NYHA class: 2.79 \pm 0.7 vs $1.38 \pm 0.49$ during follow-up, $p=0.001$. In $A R$, preoperative NYHA class was $2.93 \pm 0.9$ vs $1.48 \pm 0.75$ during follow-up, $\mathrm{p}=0.001$.

Most patients showed a positive change of ventricular function ejection fraction (AS: $32.1 \% \pm 8 \%$ vs $49 \% \pm$ $14.7 \%$, p $<0.001$, AR: $33.8 \% \pm 6.7 \%$ vs $51.2 \% \pm 10.9 \%$, $\mathrm{p}=0.001)$. Left ventricular diameters decreased in the both groups (Table 4).

\section{DISCUSSION}

The current study shows that AVR can be performed with excellent late outlook. Similarly, there is a real improvement in functional status and LV function recovery, but the operative mortality still remains high. Some efforts must be undertaken in medical management.

Table 3. Comparison between outcomes parameters of AS and AR group.

\begin{tabular}{cccc}
\hline Variable & $\mathrm{AS}(\mathrm{n}=40)$ & $\mathrm{AR}(\mathrm{n}=35)$ & $\mathrm{p}$ \\
\hline Survivors (n, \%) & $35 / 40(87.5 \%)$ & $29 / 35(82.8 \%)$ & $\mathrm{NS}$ \\
Lost & $8 / 35$ & $5 / 29$ & $\mathrm{NS}$ \\
Controlled patients (n, \%) & $27 / 35(77 \%)$ & $24 / 29(82 \%)$ & $\mathrm{NS}$ \\
Follow-up period (months) & $31.8 \pm 22$ & $61.8 \pm 45$ & 0.017 \\
NYHA class & & & \\
$-\quad \quad$ I (n, \%) & $16(59.3 \%)$ & $16(69.6 \%)$ & $\mathrm{NS}$ \\
$-\quad$ II (n, \%) & $10(37 \%)$ & $4(17.4 \%)$ & $\mathrm{NS}$ \\
$-\quad$ III (n, \%) & $1(3.7 \%)$ & $1(4.3 \%)$ & $\mathrm{NS}$ \\
- $\quad$ IV (n, \%) & 0 & $2(8.7 \%)$ & $\mathrm{NS}$ \\
$\quad$ CTI (\%) & $0.52 \pm 0.04$ & $0.54 \pm 0.06$ & 0.09 \\
LVEDD (mm) & $53.5 \pm 8.8$ & $57 \pm 8.9$ & 0.93 \\
LVESD (mm) & $38.2 \pm 9.9$ & $38.4 \pm 12.3$ & 0.5 \\
SF (\%) & $26.6 \pm 6.3$ & $28 \pm 6.5$ & 0.9 \\
EF (\%) & $49 \pm 14.7$ & $51.2 \pm 10.9$ & 0.26 \\
Late death (n, \%) & $3 / 35(8.57)$ & $3 / 29(10.3)$ & $\mathrm{NS}$ \\
NYHA & $1.38 \pm 0.49$ & $1.26 \pm 0.56$ & 0.5 \\
\hline
\end{tabular}

CTI: cardio-thoracic index, LVEDD: left ventricular end-diastolic diameter, LVESD: left ventricular end-systolic diameter, SF: shortening fraction, EF: ejection fraction, NYHA: New York Heart Association. 


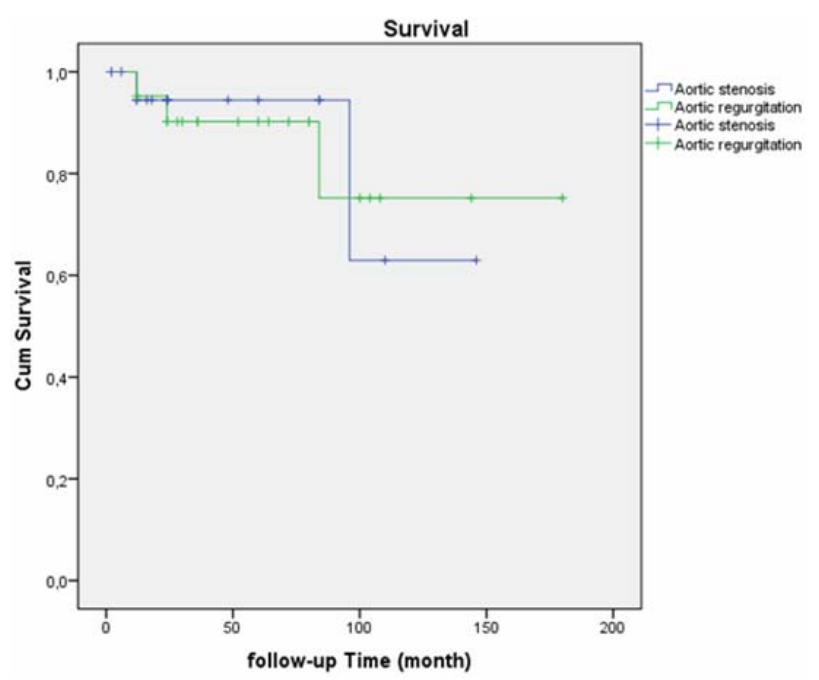

Figure 1. Kaplan-Meier survival plot after aortic valve replacement for patients with poor left ventricular function.

Table 4. Comparison of preoperative and postoperative parameters in AS and AR group.

\begin{tabular}{|c|c|c|c|c|c|c|}
\hline \multirow[b]{2}{*}{ Variable } & \multicolumn{3}{|c|}{$\operatorname{AS}(n=40)$} & \multicolumn{3}{|c|}{$\mathrm{AR}(\mathrm{n}=35)$} \\
\hline & Preop (40) & $\begin{array}{c}\text { Postop } \\
\text { (27) }\end{array}$ & $\mathrm{p}$ & Preop (35) & $\begin{array}{c}\text { Postop } \\
\text { (23) }\end{array}$ & $\mathrm{p}$ \\
\hline NYHA & $2.79 \pm 0.7$ & $1.38 \pm 0.49$ & 0.001 & $2.93 \pm 0.91$ & $1.48 \pm 0.75$ & 0.001 \\
\hline CT Index & $0.58 \pm 0.05$ & $0.52 \pm 0.04$ & 0.001 & $0.62 \pm 0.05 c$ & $0.54 \pm 0.06$ & 0.001 \\
\hline $\begin{array}{l}\text { LVESD } \\
(\mathrm{mm})\end{array}$ & $50.2 \pm 9.2$ & $38.2 \pm 9.9$ & 0.001 & $62.1 \pm 8.83$ & $38.4 \pm 12.3$ & 0.001 \\
\hline $\begin{array}{l}\text { LVEDD } \\
(\mathrm{mm})\end{array}$ & $63.6 \pm 8.9$ & $53.5 \pm 8.8$ & 0.001 & $77.6 \pm 9.8$ & $57 \pm 8.9$ & 0.001 \\
\hline SF (\%) & $17.6 \pm 4.9$ & $26.6 \pm 6.3$ & 0.002 & $16.8 \pm 4.7$ & $28 \pm 6.5$ & 0.001 \\
\hline $\mathrm{EF}(\%)$ & $32.1 \pm 8$ & $49 \pm 14.7$ & 0.001 & $33.8 \pm 6.75$ & $51.2 \pm 10.9$ & 0.001 \\
\hline
\end{tabular}

Follow-up

time (months)

$31.8 \pm 22$

$61.8 \pm 45 \quad 0.017$

NYHA: New York Heart Association, CTI: cardio-thoracic index, LVESD: left ventricular end-systolic diameter, LVEDD: left ventricular end-diastolic diameter, SF: shortening fraction, $\mathrm{EF}$ : ejection fraction.

Despite improvements in surgery, cardiology and anesthesiology over time, there is still continuing dilemmas concerning aortic valve replacement in patients with impaired left ventricular systolic function. LV dysfunction is a major prognostic factor of both the early and late outcome after surgery [5-11].

The ACC/AHA practice guidelines recommend AVR for severe aortic regurgitation patients presenting with LV dysfunction or cardiac symptoms [12]. But the most perplexing problem regarding the management of the patients with chronic AR is the optimal timing of surgery. The vast majority of patients are asymptomatic for many years during which the systolic function deteriorates progressively. By the time of symptoms develop, some patients have already developed irreversible myocardial damage and hence respond poorly after AVR. On the other hand, patients with critical AS and severe LV dysfunction constitute a more heterogeneous and even more challenging group.

Impaired function has long been recognized as a predictor of adverse outcome after AVR, but the impact of valvular pathophysiology has not been clearly defined $[11,13,14]$.

Patients with AS and low EF represent a minority (5 to $10 \%$ ) among patients with AS [15]. AS imposes an increased after-load on the LV, increasing left ventricular wall tension with subsequent ventricular hypertrophy. Uncorrected AS eventually leads to myocardial dysfunction as the hypertrophied myocardium cannot compensate the increased wall stress. The compensatory mechanism according to the Frank-Starling relation-ship fails, increasing degrees of LV dilatation result, and systolic function declines $[14,16,17]$.

Unlike AS, the patho-physiology of AR involves both volume and pressure after-load of the LV. Eccentric ventricular hypertrophy occurs in response to increased LV end-diastolic wall stress [14]. AS long-standing AR evolves, the ventricle dilates and compensates through a process called "after-load mismatch, pre-load reserve" introduced by John Ross [16,18]. Pre-load is increased as to maintain forward flow via the Frank-starling relationship. However, when preload reserve reaches a limit, the ventricle undergoes a progressive decline in pump function $[14,19]$.

Operative mortality in the current study was $12.5 \%$ among AS patients, it correlates with the results reported in contemporary study in which operative mortality rate ranged from $8 \%$ to $21 \%$ [11,20-23]. This mortality does, however, contrast with those reporters in other published studies: Chukwuemeka [24] 1.5\% bevilacqua [25] 5.7\%, Rediker [26] 0\%.

The operating results of AVR for AS patients with LV dysfunction is obviously affected by many variables. Many published reports included patients undergoing concomitant CABG [1].

Elevated creatinine, NYHA class III-IV and LV systolic diameters $>54 \mathrm{~mm}$ as independent parameter of mortality in a patient with both AS and AR [20-22]. Sharony et al. [11], however found that renal failure and advanced age are independent risk factors for mortality. In our death patients with AS (5/40), 3 have EF $<35 \%$ and mean transvalvular gradient $<30 \mathrm{mmHg}$, and creatinine level $>200 \mu \mathrm{mol} / \mathrm{l}$. all deaths have been in functional class III-IV, but only one patient had combined CABG.

Severe pulmonary hypertension (PHT) in severe AS portends a poor prognosis with a reported prevalence as high as $29 \%$ [27]. AVR was also associated with higher than usual operative mortality. Malouf J [28] 16\% and Spencer Melky J [29] 9\%. In our study, 3/5 deaths have 
severe PHT (PAPS $>60 \mathrm{mmHg}$ ).

In the opposite, an improvement in functional class was noted in most survivors. $88 \%$ were in FC NYHA IIIIV prior to surgery, after a follow-up, only $4.7 \%$ remained in NYHA III-IV. In addition EF increased significantly of approximately $17 \%$ in both groups. Clearly, patients exhibit better clinical improvement an excellent long-term survival. These data are in agreement with most authors [21-24].

It is now clear that patients with critical AS and impaired LV function fall in roughly in to one of three groups who have two different reasons for LV dysfunction. Afterload mismatch, which generally respond well to surgery and the other two groups consist of patients who have low transvalvular gradients (TVG). These patients are assumed to have coexisting cardiomyopathy in addition to myocardial dysfunction, and the effects of AVR are less beneficial. Some recent studies have focused on this subgroup [15,30-33].

Dobutamine stress echocardiography (DSE) has been proposed as a method able to evaluate the tightness of the stenosis, the severity of the LV dysfunction and its reversibility. According to a recent study, patients with LV contractile reserve have relatively low operative risk $(<5 \%)$, whereas, those without contractile reserve have a high operative mortality $(11 \%-22 \%)[30,34,35]$. But this approach has several limitations. Although the absence of contractile reserve on DSE is related to high operative mortality, it does not predict the absence of LV EF recovery in patients surviving to AVR. Most authors support the concept that the surgery should not be complicated on the basis of absence of contractile reserve alone [36].

In AR group, most of patients may not present until they have advanced heart failure with severe LV dysfunction and ventricular dilatation, so they always presented difficult management issue. Particularly, controversies exit about the questions of whether the risk of surgery is too high, and whether any improvement in LV EF and survival can't realistically be expected after successful AVR. Currently, this mortality rate ranges between $6 \%$ to $14 \%$ among patients with $\mathrm{AR}$ and poor LVEF [37-39].

In the modern area, there are many reasons that patients fare better after surgery: medical management improved substantially with use of angiotensin-converting inhibitors (ACI) and $\beta$ blockers. Operative myocardial protection becomes more sophisticated.

Compared to old prosthesis that are known to have a high gradient replacement heart valves have considerably improved with low gradient prosthesis and mechanical valves readily available, perioperative management now include use of newer inotropes such as the phosphor diesterase inhibitors milrinone. Our analysis shows that patients who died ( 6 cases) in the early outcome, have many predictor factors of worse operative risk as $4 / 6$ have LV ED $>80 \mathrm{~mm}$, markedly reduced $\mathrm{EF}<30 \%$, severe PHT (SPAP $>60 \mathrm{mmHg}$ ) and $5 / 6$ death were in NYHA FC III-IV. These candidate patients were declared as the patients with the greatest perioperative risk of death $[20,39]$.

Despite excessive operative modality, the FC status and $\mathrm{EF}$ of most patients improve after surgery. We found these results in line with the literature $[21,38,40]$. Thus, patients suffering from AR and markedly low EF, enlarged LV diameters derived benefit from surgery compared with expected evolution [21,41], so they should not be considered a contraindication to AVR. Other investigators have also observed partial improvement in $\mathrm{EF}$ and persistent dysfunction following surgery in $\mathrm{AR}$ as well as AS patients [40,42-44]. Excessive LV hypertrophy (LV mass index $>200 \%$ of normal) is the main factor that correlates with deterioration of diastolic function during late outcome. This funding is supported by many authors [33,45-47].

But some author's observations showed that LV dilatation and LV systolic dysfunction persist if LV diameters are extremely enlarged (LVEDD $\geq 80 \mathrm{~mm}$, LVESD $\geq 59$ $\mathrm{mm})$ [48-51].

\section{STUDY LIMITATIONS}

Although the data were collected prospectively, this article is prone to the inherent biases of its retrospective nature.

This is a small group of patients especially those who have markedly reduced $\mathrm{EF}$ ( $5 \%$ of AS and $35 \%$ of AR) $[15,52]$.

It is difficult to analyze our results due to the relatively small number of patients.

Operative mortality in our study is relatively high compared to recent reports.

Logically, the mortality rate must decrease because our patients are younger and they have few associated comorbidities. The main reason to explain this no-good result is the lateness of developing countries in medical management of this categorical patient, so our findings are compared to those articles published before 1985 in developed countries. We have no idea about prosthesispatient mismatch, because patients with PPM have worse functional class, reduced regression of left ventricular hypertrophy, and more adverse cardiac events after aortic valve replacement compared to patients without PPM [53, 54].

Additionally, our patients were quite heterogeneous in terms of age, etiology of rheumatic disease and follow-up duration and this may have influenced the results.

Dobutamine stress echocardiography (DSE) was not performed because it does not seem to be a useful tool in 
risk stratification, but when there is a high operative risk, we better try to inform the patient.

The small sample size and the limited number of deaths observed in early outcome and during the followup limit the quality of results and reduce the statistical power for the identification of predictive factors.

\section{REFERENCES}

[1] Cannolly, H.M., Oh, J.K., Orszulak, T.A., Osborn, S.L., Roger, V.L., Hodge, D.O., et al. (1997) Aortic valve replacement for aortic stenosis with severe left ventricular dysfunction. Prognostic indicators. Circulation, 95, 23952400. http://dx.doi.org/10.1161/01.CIR.95.10.2395

[2] Mandinov, L., Kaufmann, P. and Hess, O.M. (1998) Diagnosis and indication for aortic valve replacement in asymptomatic and symptomatic patients with aortic regurgitation. Herz, 23, 441-447. http://dx.doi.org/10.1007/BF03043405

[3] Bonow, R.O., Picone, A.L., McIntosh, C.L., Jones, M., Rosing, D.R., Maron, B.J., et al. (1985) Survival and functional results after valve replacement for aortic regurgitation from 1976 to 1983: Impact of preoperative left ventricular function. Circulation, 72, 1244-1256. http://dx.doi.org/10.1161/01.CIR.72.6.1244

[4] Wahi, S., Haluska, B., Pasquet, A., Case, C., Rimmermann, C.M. and Marwick, T.H. (2000) Exercise echocardiography predicts development of left ventricular dysfunction in medically and surgically treated patients with asymptomatic severe aortic regurgitation. Heart, 84, 606614. http://dx.doi.org/10.1136/heart.84.6.606

[5] Powell, D.E., Tunick, P.A., Rosenzweig, B.P., Freedberg, R.S., Katz, E.S., Applebaum, R.M., et al. (2000) Aortic valve replacement in patients with aortic stenosis and severe left ventricular dysfunction. Archives of Internal Medicine, 160, 1337-1341.

http://dx.doi.org/10.1001/archinte.160.9.1337

[6] Czer, L.S., Gray, R.J., Stewart, M.E., De Robertis, M., Chaux, A. and Matloff, J.M. (1988) Reduction in sudden late death by concomitant revascularization with aortic valve replacement. The Journal of Thoracic and Cardiovascular Surgery, 95, 390-401.

[7] Morris, J.J., Schaff, H.V., Mullany, C.J., Rastogi, A., McGregor, C.G., Daly, R.C., et al. (1993) Determinants of survival and recovery of left ventricular function after aortic valve replacement. The Annals of Thoracic Surgery, 56, 22-29. http://dx.doi.org/10.1016/0003-4975(93)90398-2

[8] Bonow, R.O., Dodd, J.T., Maron, B.J., O'Gara, P.T., White, G.G., McIntosh, C.L., et al. (1988) Long-term serial changes in left ventricular function and reversal of ventricular dilatation after valve replacement for chronic aortic regurgitation. Circulation, 78, 1108-1120. http://dx.doi.org/10.1161/01.CIR.78.5.1108

[9] Lund, O., Flo, C., Jensen, F.T., Nielsen, T.T., Rasmussen, B.S., Hansen, O.K., et al. (1997) Left ventricular systolic and diastolic function in aortic stenosis. Prognostic value after valve replacement and underlying mechanisms.
European Heart Journal, 18, 1977-1987. http://dx.doi.org/10.1093/oxfordjournals.eurheartj.a01520 $\underline{9}$

[10] Corti, R., Benggeli, C., Turina, M., Jenni, R., Luscher, T.F. and Turina, J. (2001) Predictors of long-term survival after valve replacement for chronic aortic regurgitation. Is M-mode echocardiography sufficient? European Heart Journal, 22, 866-873. http://dx.doi.org/10.1053/euhj.2000.2314

[11] Sharony, R., Grossi, E.A., Saunders, P., Schwartz, C.F., Ciuffo, G.B., Baumann, F.G., et al. (2003) Aortic valve replacement in patients with impaired ventricular function. The Annals of Thoracic Surgery, 75, 1808-1814. http://dx.doi.org/10.1016/S0003-4975(03)00117-6

[12] Bonow, R.O., Carabello, B.A., Chatterjee, K., De Leon Jr., A.C., Faxon, D.P., Freed, M.D., et al. (2006) ACC/ AHA 2006, guidelines for the management of patients with valvular heart disease: A report of the American college of cardiology/American Heart Association Task Force on practice Guidelines. Circulation, 114, e84-e231. http://dx.doi.org/10.1161/CIRCULATIONAHA.106.1768 57

[13] McCarthy, P.M. (2002) Aortic valve surgery in patients with left ventricular dysfunction. Seminars in Thoracic and Cardiovascular Surgery, 14, 137-143. http://dx.doi.org/10.1053/stcs.2002.32368

[14] Green, G.R. and Miller, D.G. (1997) Continuing dilemmas concerning aortic valve replacement in patients with advanced left ventricular dysfunction. The Journal of Heart Valve Disease, 6, 562-579.

[15] Clavel, M.A., Fuchs, C., Burwash, I.G., Mundigler, G., Dumesnil, J.G., Baumgartner, H., et al. (2008) Predictors of outcomes in low-flow, low-gradient aortic stenosis: Results of the multicenter TOPAS Study. Circulation, 118, S234-S242.

[16] Ross, J. and Braunwalds, E. (1968) Aortic stenosis. Circulation, 38, 61-67. http://dx.doi.org/10.1161/01.CIR.38.1S5.V-61

[17] Chizner, M.A., Pearle, D.L. and De Leon, A.C. (1980) The natural history of aortic stenosis in adults. American Heart Journal, 99, 419-424. http://dx.doi.org/10.1016/0002-8703(80)90375-0

[18] Ricci, D.R. and Mason, M.A. (1982) Ventricular performance in chronic aortic regurgitation: Application to the concept of afterload mismatch and preload reserve. Clinical Research, 30, 18A.

[19] Taniguchi, K., Kawamaoto, T., Kuki, S., Masai, T., Mitsuno, M., Nakano, S., et al. (2000) Left ventricular myocardial remodeling and contractile state in chronic aortic regurgitation. Clinical Cardiology, 23, 608-614. http://dx.doi.org/10.1002/clc.4960230812

[20] Cannolly, H.M., Oh, J.K., Schaff, H.V., Roger, V.L., Osborn, S.L., Hodge, D.O., et al. (2000) Severe aortic stenosis with low transvalvular gradient and severe left ventricular dysfunction. Results of aortic valve replacement in 52 patients. Circulation, 101, 1940-1946. http://dx.doi.org/10.1161/01.CIR.101.16.1940

[21] Rothenburger, M., Drebber, K., Tjan, T.D., Schmidt, C., Wichter, T., Scheld, H.H., et al. (2003) Aortic valve re- 
placement for aortic regurgitation and stenosis in patients with severe left ventricular dysfunction. European Journal Cardio-Thoracic Surgery, 23, 703-709. http://dx.doi.org/10.1016/S1010-7940(03)00030-7

[22] Flores-Marin, A., Gomez-Doblas, J.J., Caballero-Borrego, J., Cabrera-Bueno, F., Rodriguez-Bailon, I., Melero, J.M., et al. (2010) Long-term predictors of mortality and functional recovery after aortic valve replacement for severe aortic stenosis with left ventricular dysfunction. Revista Española de Cardiología, 63, 36-45.

[23] Rabus, M.B., Kirali, K., Kayalar, N., Yayla-Tuncer, E., Toker, M.E. and Yakut, C. (2009) Aortic valve replacement in isolated severe aortic stenosis with left ventricular dysfunction: Long-term survival and ventricular recovery. Anadolu Kardiyoloji Dergisi, 9, 41-46.

[24] Chukwuemeka, A., Rao, V., Armstrong, S., Ivanov, J. and David, T. (2006) Aortic valve replacement: A safe and durable option in patients with impaired left ventricular systolic function. European Journal CardioThoracic Surgery, 29, 133-138.

http://dx.doi.org/10.1016/j.ejcts.2005.11.028

[25] Bevilaqua, S., Gianetti, J., Ripoli, A., Paradossi, U., Cerillo, A.G., Glauber, M., et al. (2002) Aortic valve disease with severe ventricular dysfunction: Stentless valve for better recovery. The Annals of Thoracic Surgery, 74, 2016-2021. http://dx.doi.org/10.1016/S0003-4975(02)03981-4

[26] Rediker, D.E., Boucher, C.A., Block, P.C., Akins, C.W., Buckley, M.J. and Fifer, M.A. (1987) Degree of reversibility of left ventricular systolic dysfunction after aortic valve replacement for isolated aortic valve stenosis. The American Journal of Cardiology, 60, 112-118. http://dx.doi.org/10.1016/0002-9149(87)90996-9

[27] Silver, K., Aurigemma, G., Krendel, S., Barry, N., Ockene, I. and Alpert, J. (1993) Pulmonary artery hypertension in severe aortic stenosis: Incidence and mechanism. American Heart Journal, 125, 146-150. http://dx.doi.org/10.1016/0002-8703(93)90067-J

[28] Malouf, J., Enriquez-Sarano, M., Pellikka, P.A., Oh, J.K., Bailey, K.R., Chandrasekaran, K., et al. (2002) Severe pulmonary hypertension in patients with severe aortic valve stenosis: Clinical profile and prognostic implications. Journal of the American College of Cardiology, 40, 789-795. http://dx.doi.org/10.1016/S0735-1097(02)02002-8

[29] Melby, S.J., Moon, M.R., Lindman, B.R., Bailey, M.S., Hill, L.L. and Damiano, R.J. (2011) Impact of pulmonary hypertension on outcomes after aortic valve replacement for aortic valve stenosis. The Journal of Thoracic and Cardiovascular Surgery, 141, 1424-1430. http://dx.doi.org/10.1016/i.jtcvs.2011.02.028

[30] Levy, F., Laurent, M., Monin, J.L., Maillet, J.M., Pasquet, A., Le Tourneau, T., et al. (2008) Aortic valve replacement for low-flow/low-gradient aortic stenosis. Journal of the American College of Cardiology, 51, 1466-1472. http://dx.doi.org/10.1016/i.jacc.2007.10.067

[31] Monin, J.L., Monchi, M., Gest, V., Duval-Moulin, A.M., Dubois-Rande, J.L. and Gueret, P. (2001) Aortic stenosis with severe left ventricular dysfunction and low trans- valvular pressure gradients. Journal of the American College of Cardiology, 37, 2101-2107. http://dx.doi.org/10.1016/S0735-1097(01)01339-0

[32] Quere, J.P., Monin, J.L., Levy, F., Petit, H., Baleynaud, S., Chauvel, C., et al. (2006) Influence of preoperative left ventricular contractile reserve on postoperative ejection fraction in low-gradient aortic stenosis. Circulation, 113, 1738-1744.

http://dx.doi.org/10.1161/CIRCULATIONAHA.105.5688 $\underline{24}$

[33] Lamb, H.J., Beyerbacht, H.P., De Roos, A., Van Der Laarse, A., Vliegen, H.W., Leujes, F., et al. (2002) Left ventricular remodeling early after aortic valve replacement: Differential effect on diastolic function in aortic valve stenosis and regurgitation. Journal of the American College of Cardiology, 40, 2182-2188. http://dx.doi.org/10.1016/S0735-1097(02)02604-9

[34] Monin, J.L., Quéré, J.P., Monchi, M., Petit, H., Baleynaud, S., Chauvel, C., et al. (2003) Low-gradient aortic stenosis: Operative risk stratification and predictors for long-term outcome: A multicenter study using dobutamine stress hemodynamics. Circulation, 108, 319-324. http://dx.doi.org/10.1161/01.CIR.0000079171.43055.46

[35] Tribouilloy, C., Levy, F., Rusinaru, D., Gueret, P., PetitEisenmann, H., Baleynaud, S., et al. (2009) Outcome after aortic valve replacement for low-flow/low-gradient aortic stenosis without contractile reserve on dobutamine stress echocardiography. Journal of the American College of Cardiology, 53, 1865-1873. http://dx.doi.org/10.1016/j.jacc.2009.02.026

[36] Monin, J.L. and Gueret, P. (2005) Dobutamine hemodynamics for aortic stenosis with left ventricular dysfunction. Annales de Cardiologie et d Angéiologie, 54, 101111.

[37] Barbosa, M.M., Freire Claudia, M.V., Fenelon Lucia, M.A., Esteves William, A.M., Reis, G. and Nunes Maria do Carmo, P. (2009) Dobutamine stress echocardiography in asymptomatic patients with aortic regurgitation. Arquivos Brasileiros De Cardiologia, 93, 49-57.

[38] Chaliki, H.P., Mohty, D., Avierinos, J.F., Scott, C.G., Schaff, H.V., Tajik, A.J., et al. (2002) Outcomes after aortic valve replacement in patients with severe aortic regurgitation and markedly reduced left ventricular function. Circulation, 106, 2687-2693. http://dx.doi.org/10.1161/01.CIR.0000038498.59829.38

[39] Meurs, A.A., Gründemann, A.M., Bezemer, P.D., Geldof, W.C., Zienkowicz, B.S., Ong, S.T., et al. (1985) Early and 8 years results of aortic valve replacement: A clinical study of 232 patients. European Heart Journal, 6, 870881 .

[40] Bhudia, S.K., McCarthy, P.M., Kumpati, G.S., Helou, J., Hoercher, K.J., Rajeswaran, J., et al. (2007) Improved outcomes after aortic valve replacement surgery for chronic aortic regurgitation with severe left ventricular dysfunction. Journal of the American College of Cardiology, 49, 1465-1471. http://dx.doi.org/10.1016/i.jacc.2007.01.026

[41] Scognamiglio, R., Negut, C., Palisi, M., Fasoli, G. and Dalla-Volta, S. (2005) Long-term survival and functional 
results after aortic valve replacement in asymptomatic patients with chronic severe aortic regurgitation and left ventricular dysfunction. Journal of the American College of Cardiology, 45, 1025-1030. http://dx.doi.org/10.1016/j.jacc.2004.06.081

[42] Taniguchi, K., Nakano, S., Kawashima, K., Yakai, K., Kawamoto, T., Sakaki, S., et al. (1990) Left ventricular ejection performance, wall stress and contractile state in aortic regurgitation before and after aortic valve replacement. Circulation, 82, 798-807. http://dx.doi.org/10.1161/01.CIR.82.3.798

[43] Hanayama, N., Christakis, G.H., Mallidi, H.R., Rao, V., Cohen, G., Goldman, B.S., et al. (2005) Determinants of incomplete left ventricular mass regression following aortic valve replacement. Journal of Cardiac Surgery, 20, 307-313. http://dx.doi.org/10.1111/j.1540-8191.2005.200485.x

[44] Roman, M.J., Klein, L., Devereux, R.B., Kligfield, P., Niles, N.W., Hochreiter, C., et al. (1989) Reversal of left ventricular dilatation, hypertrophy and dysfunction by valve replacement in aortic regurgitation. American Heart Journal, 118, 553-563. http://dx.doi.org/10.1016/0002-8703(89)90272-X

[45] Taniguchi, K., Takahashi, T., Toda, K., Matsue, H., Shudo, Y., Shintni, H., et al. (2007) Left ventricular mass: Impact of left ventricular contractile function and its reversibility in patients undergoing aortic valve replacement. European Journal Cardio-Thoracic Surgery, 32, 588-595. http://dx.doi.org/10.1016/j.ejcts.2007.07.003

[46] Carabello, B., Usher, B.W., Hendrix, G.H., Assey, M.E., Crawford, F.A. and Leman, R.B. (1987) Predictors of outcomes for aortic valve replacement in patients with regurgitation and left ventricular dysfunction: A change in measuring stick. Journal of the American College of Cardiology, 10, 991-997. http://dx.doi.org/10.1016/S0735-1097(87)80335-2

[47] Villari, B., Sossalla, S., Ciampi, Q., Petruzziello, B., Turina, J., Schneider, J., et al. (2009) Persistent diastolic dysfunction late after valve replacement in severe aortic regurgitation. Circulation, 120, 2386-2392. http://dx.doi.org/10.1161/CIRCULATIONAHA.108.8126 $\underline{85}$

[48] Vaquette, B., Corbineau, H., Laurent, B., Lelong, B., Langanay, T., De Place, C., et al. (2005) Valve replacement in patients with critical aortic stenosis and depressed left ventricular function: Predictors of operative risk, left ventricular function recovery, and long term outcome. Heart, 91, 1324-1329. http://dx.doi.org/10.1136/hrt.2004.044099

[49] Otto, C.M. (2006) Valvular aortic stenosis: Disease severity and timing of intervention. Journal of the American College of Cardiology, 47, 2141-2151. http://dx.doi.org/10.1016/j.jacc.2006.03.002

[50] Hanayama, N., Christakis, G.T., Mallidi, H.R., Joyner, C.D., Fermes, S.E., Morgan, C.D., et al. (2002) Patient prosthesis mismatch is rare after aortic valve replacement: Valve size may be irrelevant. The Annals of Thoracic Surgery, 73, 1822-1829. http://dx.doi.org/10.1016/S0003-4975(02)03582-8

[51] Blais, C., Dumesnil, J.G., Baillot, R., Simard, S., Doyle, D. and Pibarot, P. (2003) Impact of valve prosthesis-patient mismatch on short-term mortality after aortic valve replacement. Circulation, 108, 983-988. http://dx.doi.org/10.1161/01.CIR.0000085167.67105.32

[52] Tamas, E., Nylander, E. and Olin, C. (2005) Are patients with isolated chronic aortic regurgitation operated in time? Analysis of survival data over a decade. Clinical Cardiology, 28, 329-332. http://dx.doi.org/10.1002/clc.4960280705

[53] Pibarot, P. and Dumesnil, J.G. (2006) Prosthesis-patient mismatch: Definition, clinical impact, and prevention. Heart, 92, 1022-1029. http://dx.doi.org/10.1136/hrt.2005.067363

[54] Mohty, D., Malouf, J.F., Girard, S.E., Schaff, H.V., Grill, D.E., Enriquez-Sarano, M.E., et al. (2006) Impact of prosthesis-patient mismatch on long term survival in patients with small St Jude Medical mechanical prostheses in the aortic position. Circulation, 113, 420-426. http://dx.doi.org/10.1161/CIRCULATIONAHA.105.5467 $\underline{54}$ 